\title{
Васильченко Д.В. \\ Рост продаж настольных игр: правильное позиционирование или случайное стечение обстоятельств?
}

\author{
Государственный Университет Управления
}

(Россия, Москва)

doi: 10.18411/lj-04-2021-204

\section{Аннотация}

Данная статья посвящена анализу стремительно набирающей популярность индустрии настольных игр. Целью исследования является рассмотрение индустрии в течение последних лет и анализ методов продвижения. Изучен рынок настольных игр, проанализирован мировой опыт, а также положение рекламы и продвижения игр в реалиях российской действительности. Также в статье рассматриваются прогнозы индустрии в перспективе. Сделано заключение о состоянии российского рынка настольных игр.

Ключевые слова: настольные игры, развлечение, культура, продвижение, тенденции рынка настольных игр.

\section{Abstract}

This article is devoted to the analysis of the rapidly growing popularity of the board game industry. The purpose of the study is to review the industry in recent years and analyze the methods of promotion. The market of board games is studied, the world experience is analyzed, as well as the position of advertising and promotion of games in the realities of Russian reality. The article also discusses industry forecasts in the future. The conclusion about the state of the Russian market of board games is made.

Keywords: board games, entertainment, culture, promotion, trends of the board games market.

Последние годы индустрия настольных игр наслаждается своей востребованностью и популярностью. Начиная с обычного принятия данного рынка как элемента культуры и заканчивая небывалым объемом продаж в период пандемии, настольные игры только набирают обороты своей популярности и не собираются сдавать назад ближайшее десятилетие, как минимум. Данный рынок оказался самым необходимым в период самоизоляции: игры сближают семьи, отвлекают людей от тяжелого информационного фона и постоянного нахождения перед экраном гаджетов. Огромное количество статей написаны на тему причин резкой популяризации настольных игр, сейчас же рассуждение пойдет не только об этом, но и о делах индустрии в данный момент, что происходит в ней сейчас и к чему она стремится.

На данный момент рынок настольных игр процветает и вовсю пожинает плоды своей популярности. Ежегодно выпускаются все новые непохожие друг на друга игры, их линейка переступила порог в 2000 единиц, а продажи самых популярных на данный момент игр, например, «Каркассон» или «Колонизаторы» составили 15 миллионов экземпляров только на 2019 год. Такой оборот и частота производства связаны с тем, что создание настольной игры обходится дешевле, чем создание игры компьютерной. Однако, стоит отметить, что себестоимость запуска в производство одной игры может доходить до 1,5 миллионов рублей, так считается ли такой бизнес прибыльным? Можно с уверенностью сказать, что такие траты точно себя окупят, так как на 2019 год только в России объем рынка составил 1,5 миллиона долларов. Не стоит забывать и про вклады Российской сети продажи настольных игр Мосигра, чьи инвестиции составляют 300 миллионов рублей. Как можно заметить, рынок только набирает обороты своего развития, и производители могут по-настоящему радоваться такой динамике. 
Статистика выглядит многообещающе и даже немного нереально, смотря на нее, можно с уверенность сказать, что рынок явно не собирается уходить на покой. Следует разобраться, что могло поспособствовать такому росту продаж, как именно происходило продвижение, вызвавшее в людях необходимость приобретения настольных игр.

Самым главным и основным фактором становления настольных игр по праву считается глобализация, которая привела к появлению современных технологий. С внедрением гаджетов и цифровизацией нашего мира настольные игры обрели второе дыхание, превратившись из интеллектуальных поединков в настоящие схватки со своими неизученными мирами и героями. Цифровые технологии показали, насколько прекрасными могут быть игры. Теперь, вместо нескольких однотипных фишек и игрового поля мы имеем целые вселенные, наполненные мелкими деталями, огромным количеством различных персонажей, отличающимися и непохожими друг на друга историями, которые, само собой, не могут уместиться в одну коробку, и эти игры имеют бесчисленное количество продолжений и перевыпусков. Также немаловажным изменением стала смена восприятия этих игр народом. Отношение людей к настольным играм прошло огромный путь, по-настоящему эволюционировав. В былые времена люди считали настольные игры несерьезным занятием, общественность считала, что игры не несут в себе ничего серьезного, это лишь хобби, занятиеоднодневка, в этом нет никакого практического назначения, они нужны просто, чтобы отвлечь ребенка, либо весело провести время в компании близких. С течением времени люди начали замечать, что и настольные игры приносят деньги, причем, немалые. Устраиваются различные соревнования, турниры, существуют съезды и конференции. Из простого течения, тренда, настольные игры выросли в настоящую культуру, со своими правилами и принципами.

Встречи любителей настольных игр проводятся на протяжении многих лет, и с каждым разом становятся более масштабнее, не говоря о различных турнирах и состязаниях: например, в прошлом году выставку-ярмарку настольных игр в Эссене Internationale Spieltage Spiel посетило 150 тысяч гостей. На мировом уровне проводятся целые премии и награждения, так игра «Колонизаторы» получила две награды "Лучшая игра в жанре фэнтези и научной фантастики по версии Origins" и звание "Игра года" в Польше. Награды можно получить если игра имеет понятные, доступные правила, захватывающий сюжет и положительную оценку игроков, здесь абсолютно неважно, сколько экземпляров было продано или сколько удалось получить с продаж игры. Но, опуская награждение начинающих производителей и возвращаясь к мировой арене, кто является мастодонтом производства настольных игр? Более 70 \% рынка игр принадлежит зарубежным компаниям, в частности немецким и американским. С развитием технологий отпала необходимость образования компаний для создания игр, собственную игру можно выпустить онлайн, попросив помощи у людей. В таком направлении сейчас развивается Kickstarter - платформа, на которой любой человек может описать свою бизнес-идею, а все заинтересованные могут проспонсировать проект любой суммой, таким образом в прошлом году одному проекту настольной игры удалось собрать 6 миллионов долларов на реализацию.

В России индустрия настольных игр стремительно развивается, и уже становится неотъемлемой частью нашей культуры. Самыми сильными компаниями рынка на сегодняшний день являются Мосигра и Мир хобби: доля первой составляет $12 \%$, последней $-10 \%$. Мосигра является титаном в своей отрасли, ей принадлежит 73 магазина в 34 городах России и СНГ, а ежегодный оборот доходит до 600 миллионов рублей. В нашей стране также проводятся различные форумы и встречи, самым популярным считается «Граникон», в котором принимают участие разработчики настольных игр, а игры-победители пускают в производство. Пообщавшись на данном конвенте с известными издателями настольных игр России, журнал «Geekster» выяснил 
у Николая Пегасова, издателя компании Hobby World, что самыми популярными жанрами настольных игр этого года в нашей стране были стортеллинг и детективы; обычно и то и другое смещено на периферию. Люди хотят игры, в которые рассказываются какие-то интересные сюжеты. Каждый год в мировом обороте выпускается $15 \%$ отечественных игр, следовательно, существует огромная вероятность того, что победитель обычного съезда любителей игр в Москве может стать всемирно известным разработчиком. Спонсором данного мероприятия также выступает Мосигра, и стоит отдать им должное, благодаря данной сети сейчас настольные игры продаются в специализированных магазинах, а не в отделе канцтоваров, как раньше, теперь магазинам, продающим исключительно настольные игры, принадлежит 20\% рынка, а Мосигра продолжает приносить прибыль в размере 70 миллионов рублей. Ждет ли нас такая же положительная динамика в будущем?

Индустрия настольных игр только начинает расти и развиваться, в сравнении с другими, она еще не достигла своего пика, специалисты предсказывают рост продаж на 40\% через 3 года. То же можно сказать про рынок в целом: по прогнозам, доля компаний на рынке должна увеличиться до $30 \%$ в течение следующих 5 лет. Сейчас в настольные игры можно играть везде: кафе, парки, кальянные, огромное количество заведений предлагает игры как бесплатное дополнение к отдыху, тем самым стимулируя желание людей приобрести эти игры, чтобы можно было так же интересно проводить время дома. Говоря о самих играх, издатель компании-производителя настольных игр «Звезда», Константин Комаров, гарантирует, что в следующем году самым популярным сюжетом для игр будет киберпанк. Опять воскресают пирать эта тема неубиваемая, она как волна приходит и уходит. В следующем году будет достаточное количество пиратских игр. Будут открываться все новые точки специализированных магазинов, все большее количество людей будут выигрывать премии и воплощать свои идеи в реальность, а дальнейшее развитие технологий поможет исполнить даже самые безумные идеи.

Популяризация настольных игр привлекла в индустрию огромное количество игроков, некоторые из них даже не подозревали о пристрастии к данной культуре, пока настольные игры не начали появляться везде. Это сыграло на руку «ветеранам» индустрии, так как резкий масштабный наплыв новых игроков гарантирует долговечность рынка, чьи онлайн-продажи за этот год превысили $600 \%$. Естественно, такому скачку очень поспособствовала нынешняя эпидемиологическая обстановка: во время самоизоляции количество людей, приобретающих и играющих в игры составило $83 \%$. Отходя от онлайн-шопинга, следует отметить, что и физические магазины еще держатся и принимают до полутора тысяч человек в час, если речь идет о центре города. Узнают люди о выходе новых игр в основном, через различные съезды, конференции, форумы и игротеки, то есть BTL-акции. Во многом скачок продаж настольных игр обязан антикафе. Выглядит все это как самое гениальное и оригинальное решение: большая компания друзей приходит в кафе, делает себе чай, берет печенье, и играет в самые разнообразные игры хоть до закрытия заведения, очевидно, что после этого многие из них приобретут данные игры в личное пользование.

Свою популярность индустрия приобрела не так давно, поэтому сейчас еще тяжело рассматривать тенденцию ее развития, погружаясь во все детали и нюансы, так как их не так много. Можно сказать, что сейчас индустрия так популярна из-за нынешней эпидемиологической ситуации, ей просто повезло, но, ссылаясь на утверждения специалистов, рынок настольных игр давно шел к признанию, а самоизоляция ускорила этот процесс, не просто дав индустрии второе дыхание на короткий срок, но и по-новому открыв данную культуру для новых потребителей, которые обеспечат рынку востребованность на десятилетия вперед. Конечно, пока о 
таком стоит лишь догадываться, но, смотря на прогнозы экспертов, хочется верить, что индустрию ждут долгие годы процветания.

$* * *$

1. Кибкало Д. Особенности развития настольных игр в России: чем мы отличается от Европы Режим доступа: https://vc.ru/flood/39026-osobennosti-razvitiya-rynka-nastolnyh-igr-v-rossii-chem-myotlichaemsya-ot-evropy

2. Горелова Е. Продажи настольных игр растут в кризис - Режим доступа: https://www.vedomosti.ru/management/articles/2015/04/24/prodazhi-nastolnih-igr-rastut-v-krizis

3. Сеть магазинов настольных игр «Мосигра» - Режим доступа: http://mosigra.com/investor/

4. Борисенко М. В., Махмутова Э. А. Антикафе как явление современной культуры. Понятийное содержание слова - Режим доступа: https://elar.urfu.ru/bitstream/10995/85376/1/978-5-7996-24224_007.pdf

5. Редакция журнала КАНОБУ. Настольные игры оказываются на столах россиян даже чаще, чем борщ! - Режим доступа: https://kanobu.ru/articles/nastolnyie-igryi-okazyivayutsya-na-stolah-rossiyandazhe-chasche-chem-borsch-368494/

6. Лудковская А. Россияне отдыхают от гаджетов, играя в настольные игры: продажи настольных игр и пазлов выросли - Режим доступа: https:/www.npd.com/wps/portal/npd/us/news/pressreleases/2020/russians-take-a-break-from-gadgets-by-playing-board-games-sales-of-board-games-andpuzzles-grew-40-percent/

7. Анохин А. Индустрия растет быстрее, чем мы ожидали: блиц с издателями на Игроконе 2019 Режим доступа: https:/geekster.ru/base-info/interview/blits-s-izdatelyami-na-igrokone-2019/ 